\title{
Differences in the relationship between BMI and percentage body fat between Japanese and Australian-Caucasian young men
}

\author{
Masaharu Kagawa ${ }^{1}$, Deborah Kerr ${ }^{1}$, Hayato Uchida $^{2}$ and Colin W Binns ${ }^{1 *}$ \\ ${ }^{1}$ School of Public Health, Curtin University of Technology, Perth, Australia \\ ${ }^{2}$ School of Human Science and Environment, University of Hyogo, Japan
}

(Received 28 July 2005 - Revised 12 December 2005 - Accepted 10 January 2006)

\begin{abstract}
This cross-sectional study aimed to determine ethnic and environmental influences on the relationship between BMI and percentage body fat, using a sample of 144 Japanese and 140 Australian-Caucasian men living in Australia, and eighty-eight Japanese men living in Japan. Body composition was assessed by anthropometry using standard international methods (International Society for the Advancement of Kinanthropometry protocol). Body density was predicted using Durnin and Womersley's (1974) equation, and percentage body fat was calculated from Siri's (1961) equation. Significant $(P<0.05)$ ethnic differences in stature, body mass and BMI were observed between Japanese and Australian men, but no ethnic differences were observed in their percentage body fat and height-corrected sum of skinfold thicknesses. No differences were found in the BMI-percentage body fat relationship between the Japanese subjects living in Australia and in Japan. Significant $(P<0.05)$ ethnic differences in the BMI-percentage body fat relationship observed from a comparison between pooled Japanese men (aged $18-40$ years, BMI range $16 \cdot 6-32 \cdot 8 \mathrm{~kg} / \mathrm{m}^{2}$ ) and Australians (aged $18-$ 39 years, BMI range $16 \cdot 1-31 \cdot 4 \mathrm{~kg} / \mathrm{m}^{2}$ ) suggest that Japanese men are likely to have a greater percentage body fat than Australian men at any given BMI value. From the analyses, the Japanese men were estimated to have an equivalent amount of body fat to the Australian men at BMI values that were about 1.5 units lower than those of the Australians $\left(23.5 \mathrm{~kg} / \mathrm{m}^{2}\right.$ and $28.2 \mathrm{~kg} / \mathrm{m}^{2}$, respectively). It was concluded that Japanese men have greater body fat deposition than Australian-Caucasians at the same BMI value. Japanese men may therefore require lower BMI cut-off points to identify obese individuals compared with Australian-Caucasian men.
\end{abstract}

Body mass index: Body fat: BMI cut-off points: Japanese: Australian: Men

Obesity is one of the most rapidly increasing health problems in the world, not only in developed countries, but also in less affluent economies. The prevention and treatment of obesity are major issues in public health because of the relationship of obesity with other chronic diseases, including diabetes, various cancers, hypertension and CVD.

Because of its convenience and high specificity in detecting subjects with a high percentage body fat (\%BF; Roche, 1996), BMI (body mass $(\mathrm{kg}) /$ height $(\mathrm{m})^{2}$ ) has been frequently used as an indicator of relative fatness and classification of obesity. The WHO (1997) has proposed BMI cut-off points to be used as the universal standard for a classification of obesity (Table 1). In Japan, the Japanese Society for the Study of Obesity (JASSO) has proposed new Japanese-specific BMI cut-off points (similar to the WHO classification) that have since been accepted as the standard classification for obesity in Japan (Matsuzawa et al. 2000; Table 1). Using the JASSO classification, the National Nutrition Survey reported that the proportion of Japanese men with a BMI over 25 has increased 1.5 times between 1982 and 2002 in all age groups, and approximately $30 \%$ of men aged 30-69 years old are classified as 'obese' (Kenkou Eiyou Jouhou Kenkyukai, 2003).
The use of BMI in this way has a number of limitations, including its inability to distinguish between fat mass and non-fat mass (Norgan \& Ferro-Luzzi, 1982; Garn et al. 1986; Ross et al. 1988). These limitations may become an important issue when comparing ethnic groups with distinctively different body proportions or physiques. Several studies have suggested that the relationship between BMI and \%BF (i.e. the $\mathrm{BMI}-\% \mathrm{BF}$ relationship) varies with age, gender and ethnicity (Schaefer et al. 1998; Deurenberg et al. 2002; Chang et al. 2003). Asian individuals, including Chinese, Malays and Japanese, have more body fat than Caucasians at the same BMI values (Deurenberg et al. 1998, 2003; Gallagher et al. 2000; Ko et al. 2001). Moreover, other studies have also confirmed that Asians have higher morbidity at lower BMI values than Caucasians (Bei-Fan, 2002; Deurenberg-Yap et al. 2002; Jia et al. 2002; Lee et al. 2002; Li et al. 2002; Moon et al. 2002). Deurenberg et al. (2002) suggested differences in body build between Asians and Caucasians, including differences in relative leg-to-trunk length, slenderness and muscularity, as some of the reasons for this difference in the BMI-\%BF relationship between ethnic groups. The same group further suggested differences in the

Abbreviations: \%BF, percentage body fat; DXA, dual energy X-ray absorptiometry; ISAK, International Society for the Advancement of Kinanthropometry; JASSO, Japanese Society for the Study of Obesity; TEM, technical error of measurement; WPRO, Western Pacific Region of WHO.

* Corresponding author: Professor C. Binns, fax +61-8-9266-2958, email c.binns@curtin.edu.au 
Table 1. Differences in cut-off points for obesity between available BMI classifications

\begin{tabular}{|c|c|c|c|c|}
\hline BMI & JASSO (1999) & WHO (1997) & BMI & WPRO (2000) \\
\hline$<18.5$ & Underweight & Underweight & $<18.5$ & Underweight \\
\hline $18 \cdot 5 \leq-<25$ & Normal range & Normal range & $18.5 \leq-<22.9$ & Normal range \\
\hline $25 \leq-<30$ & Obese class I & Pre-obese & $23 \leq-<24.9$ & Overweight (at risk) \\
\hline $30 \leq-<35$ & Obese class II & Obese class I & $25 \leq-<29.9$ & Obese class I \\
\hline $35 \leq-<40$ & Obese class III & Obese class II & $30 \leq$ & Obese class II \\
\hline $40 \leq$ & Obese class IV & Obese class III & & \\
\hline
\end{tabular}

JASSO (1999): The Japan Society for the Study of Obesity proposed BMI cut-off points specifically for the Japanese population (Matsuzawa et al 2000).

WHO (1997): The WHO proposed the definition of obesity at a WHO Consultation on Obesity convened in Geneva (WHO, 1997).

WPRO (2000): The Steering Committee of the Regional office for the Western Pacific Region of WHO, the International Association for the Study of Obesity (IASO), and the International Obesity Task Force (IOTF) proposed BMI cut-off points that are suitable for populations living in the Asia-Pacific region (WHO/IASO/IOTF, 2000).

BMI-\%BF relationship between two Chinese populations living in different countries (Deurenberg et al. 2002). This may indicate environmental influences on body physique.

These studies suggest that, in the classification of obesity, population-specific cut-off points for BMI should be used based on corresponding levels of total body fatness for each ethnic population. To reflect such ethnic differences in the BMI-\%BF relationship, a new BMI classification was proposed specifically for the population living in the Asian-Pacific region (Western Pacific Region of WHO (WPRO); WHO/IASO/IOTF, 2000; Table 1). In addition, the WHO has recently proposed BMI values of $23,27.5,32.5$ and $37.5 \mathrm{~kg} / \mathrm{m}^{2}$ as the cut-off points that indicate the need for public health action to prevent health risks for Asian populations (WHO, 2004).

Until now, only one study has examined ethnic differences in the BMI-\%BF relationship in Japan, and this study was restricted to middle-aged men and women (Gallagher et al. 2000). From assessment of body composition using dual energy X-ray absorptiometry (DXA), Japanese individuals are likely to have a higher \% BF than a Caucasian population at any given BMI value. There have, however, been no published studies assessing this relationship in younger Japanese adults.

The objective of the present study was to determine whether ethnic differences exist in the BMI-\%BF relationship in young Japanese and Australian-Caucasian men living in Australia, and in Japanese men living in Japan.

\section{Method}

\section{Subjects}

The inclusion criteria for the study were for the subjects to be men aged between 18 and 40 years old. Japanese subjects were defined as those holding Japanese nationality who recognized themselves to be of Asian background. Australian subjects were included if they identified themselves as Australian and recognized themselves as being of 'Caucasian' (Europid) ethnic background, rather than Asian, Hispanic, Black or Aboriginal/Torres Strait Islanders. Using convenience sampling, a total of 144 healthy Japanese and 140 Australian-Caucasian men living in Australia (Perth, Western Australia) and eighty-eight Japanese men living in Japan (Himeji, Hyogo Prefecture) were recruited and included in the statistical analysis. A total of $79 \%$ of the Japanese men whose data were obtained in Australia reported that they had lived in Australia for less than 1 year. The median duration of stay in Australia was 3 months.

The study was approved by the Human Research Ethics Committee of Curtin University of Technology and adhered to the principles of medical research established by the National Health and Medical Research Council (1999). Informed consent was obtained from each subject prior to participation in the study.

Body composition of the subjects was measured by anthropometry using the protocol of the International Society for the Advancement of Kinanthropometry (ISAK) (Norton \& Olds, 1996). The method was chosen because of its portability and cost-efficiency compared with other methods, such as DXA and underwater weighing, to collect data in different countries. Comparing DXA results obtained from different machines and manufacturers with varying software versions is problematic (Fogelholm \& Lichtenbelt, 1997; Kistorp \& Svendsen, 1998). Therefore, anthropometry that was carried out by anthropometrists with a known level of technical error of measurements (TEM) was chosen in the current study.

Measurements included height, body mass, eight skinfold thicknesses (triceps, subscapular, biceps, iliac crest, supraspinale, abdominal, front thigh, medial calf), five girths (arm relaxed, arm flexed and tensed, waist, hip, calf) and two bone breadths (humerus, femur). Height and body mass were measured without shoes. All subjects were asked to wear light clothing, such as shorts and a T-shirt. Japanese and Australian-Caucasian men living in Australia were measured by a level 3 anthropometrist accredited by ISAK. The level 3 anthropometrist demonstrated an intratester TEM of within $5 \%$ for skinfolds and within $1 \%$ for other measurements, as recommended by ISAK (Gore et al. 1996), from duplicate anthropometric measurements using twenty randomly chosen subjects. The measurements of Japanese men living in Japan were made by the same level 3 anthropometrist and three level 1 anthropometrists. All participating level 1 anthropometrists demonstrated acceptable limits of TEM (an inter-tester TEM of within $10 \%$ for skinfolds and within $2 \%$ for other measurements, and an intra-tester TEM of within $7.5 \%$ for skinfolds and within $1.5 \%$ for other measurements), as recommended (Gore et al. 1996), prior to their involvement in data 
collection. All anatomical landmarks were located and marked by the level 3 anthropometrist (M. K.).

The height-corrected sum of skinfold thicknesses was calculated to adjust ethnic differences in height between subjects:

Height-corrected sum of skinfold

$$
=\Sigma X_{1} \times(170 \cdot 18 / \text { height in } \mathrm{cm})
$$

where $\Sigma X_{1}=$ triceps + subscapular + biceps + supraspinale + iliac crest + abdominal + front thigh + medial calf skinfolds in millimetres.

In order to determine \% BF using anthropometry, body density is first calculated using a prediction equation and then converted into \%BF values. In the current study, body density was predicted using an equation developed by Durnin and Womersley (1974):

$$
\text { Body density }=1 \cdot 1765-0 \cdot 0744\left(\log _{10} X_{1}\right) ;
$$

where $X_{1}=$ triceps + biceps + subscapular + iliac crest skinfolds in millimetres.

Body fat was predicted using Siri's \%BF prediction equation (Siri, 1961). Although Asians were suggested to have a fat-free mass density greater than the assumed value (i.e. $1 \cdot 1 \mathrm{~g} / \mathrm{ml}$ ), no significant ethnic differences were observed between Asian and Caucasian men (Werkman et al. 2000; Deurenberg-Yap et al. 2001). A previous study comparing $\% \mathrm{BF}$ results obtained from whole-body scanning by DXA and $\% \mathrm{BF}$ calculated from anthropometry showed comparable mean limits of agreement (Bland \& Altman, 1986) of 0.0 (2 SD 5.9) for the Japanese men living in Australia and - 0.2 (2 SD 6.1) for the Australian-Caucasian group, respectively (Kagawa et al. 2003).

The SPSS statistical package for Windows (version.10.0, 1999; SPSS Inc, Chicago, IL, USA) was used for all statistical analysis. Significant differences in age were observed between the study groups. In order to adjust for the possible influence of age, ANCOVA with Bonferroni test was conducted to examine ethnic differences in the measured variables. A linear regression analysis was conducted using \% BF calculated from anthropometry as the dependent variable, BMI and age as independent variables and ethnicity as a fixed variable ( $1=$ Japanese men, $0=$ Australian-Caucasian men). The data were transformed using natural logarithms to normalize the data prior to determining the BMI-\%BF relationship. Furthermore, the specificity and sensitivity analysis was conducted using the WHO and WPRO BMI cut-off points.

\section{Results}

Table 2 shows the ages and results of assessment of body composition for the subjects. After adjusting for age, there were significant $(P<0.05)$ ethnic differences in stature, body mass and BMI. Australian-Caucasian men also had a significantly greater sum of skinfold thicknesses than did Japanese men living in Australia $(P<0.05)$, the difference remaining after differences in height had been corrected for (i.e. height-corrected sum of eight skinfolds; $P<0.05$ ).

A regression analysis was undertaken to determine ethnic differences in the BMI-\%BF relationship. As there was no significant difference in the $\mathrm{BMI}-\% \mathrm{BF}$ relationship between Japanese individuals living in Japan and living in Australia, the two groups were combined ( $n$ 232). Figure 1 is a scatter plot of the BMI-\%BF relationships in each group after natural $\log$ transformation. Significant $(P<0 \cdot 05)$ ethnic differences in the BMI-\%BF relationship between the Japanese and Australian groups were observed. In comparison to the AustralianCaucasian men, Japanese men showed significantly greater $\% \mathrm{BF}$ at any given $\mathrm{BMI}$ value.

From a linear regression analysis, 'best fit' \%BF prediction equations for Japanese and Australian men were determined using age and BMI as independent variables and also assessed ethnic differences in the interaction. Age did not have a significant impact on the relationship and no ethnic difference in interaction was observed, this therefore being excluded from the final regression equation. The final equation was: $\mathrm{Ln}$ $\% \mathrm{BF}=-3 \cdot 321-0 \cdot 123^{*} \quad$ (Ethnicity; $1=$ Japanese, $\quad 0=$ Australian $)+1.941^{*}($ Ln BMI $),\left(R^{2}=0.548\right.$, SEE $\left.=0.21\right)$, where $\mathrm{Ln}=$ natural $\log$. A variable 'Ethnicity' had a standard error of 0.024 and $95 \%$ CI of 0.08 and $0.17 . z Z$

Using these equations, \%BF was estimated for BMI values of 20,25 and $30 \mathrm{~kg} / \mathrm{m}^{2}$, which are the BMI levels classified as average, overweight and obese, respectively by the WHO. At a BMI of $20 \mathrm{~kg} / \mathrm{m}^{2}$, the $\%$ BF of Japanese and Australian men was $13.7 \%$ and $12.1 \%$, respectively. At a BMI of $25 \mathrm{~kg} / \mathrm{m}^{2}$, their $\% \mathrm{BF}$ were $21 \cdot 1$ and $18 \cdot 7$, respectively, and at a BMI

Table 2. Results of body composition assessment obtained by anthropometry

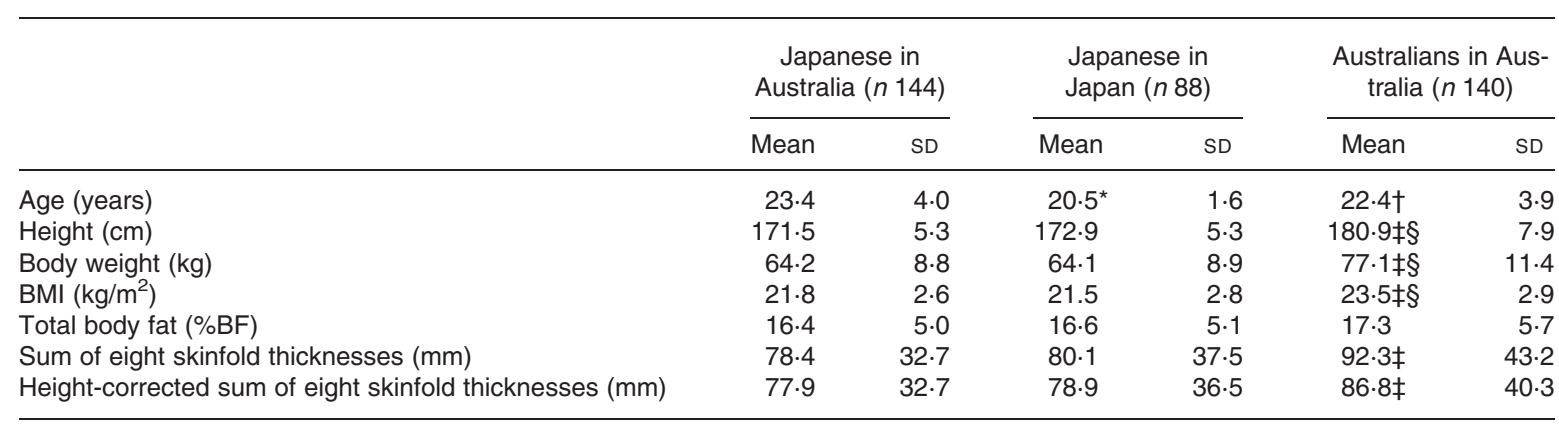

* Significantly different from Japanese living in Australia at the 0.05 level using ANOVA.

† Significantly different from Japanese living in Japan at the 0.05 level using ANOVA.

$\ddagger$ Significantly different from Japanese living in Australia at the 0.05 level using ANCOVA.

$\S$ Significantly different from Japanese living in Japan at the 0.05 level using ANCOVA. 


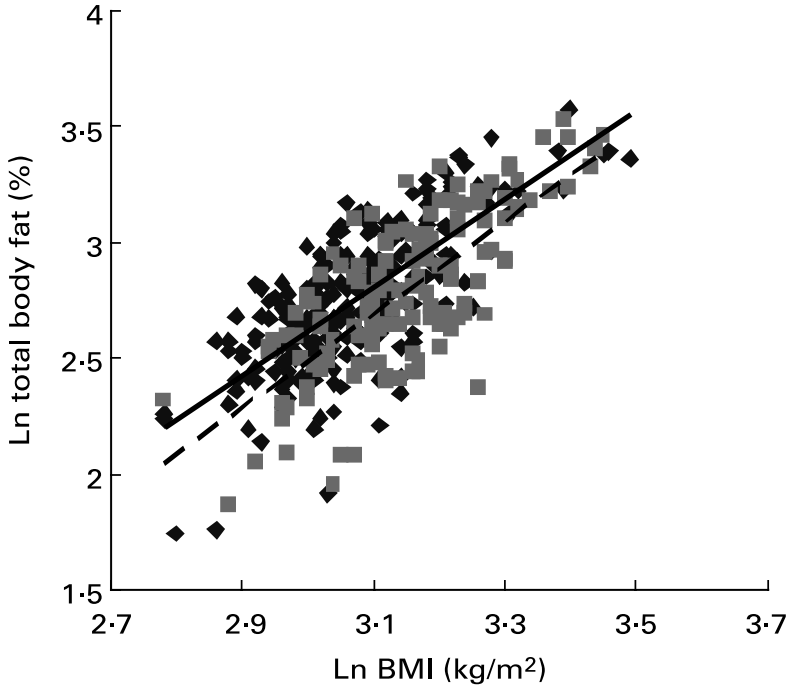

Fig. 1. Ethnic differences in the relationship between BMI and percentage body fat (\%BF) between Japanese and Australian-Caucasian men were plotted using natural log-transformed BMI (Ln BMI) against Ln \%BF. The results showed that Japanese men had a greater \%BF at any given BMI point. The fitted equation from regression analysis was $\mathrm{Ln} \% \mathrm{BF}=-3.321+1.941$ $($ Ln $\quad \mathrm{BMI})+0.123$ (Ethnicity), where Japanese $=1$ and AustralianCaucasian $=0\left(R^{2}=0.548\right.$, SEE $\left.=0.21\right) . \diamond$, Japanese males; $\square$, Australian males. - , Japanese; - -, Australian.

of $30 \mathrm{~kg} / \mathrm{m}^{2}$, the results were $30.1 \%$ for Japanese and $26.6 \%$ for Australian-Caucasian men respectively.

To determine BMI values that reflect the $\% \mathrm{BF}$ of each ethnic group, $\% \mathrm{BF}$ values of Australian men at BMI values of 25 and $30 \mathrm{~kg} / \mathrm{m}^{2}$ were entered into the above prediction equation for Japanese men. The resulting BMI values were 23.5 and $28.2 \mathrm{~kg} / \mathrm{m}^{2}$, respectively. This suggests that Japanese men require BMI values of about $1.5 \mathrm{~kg} / \mathrm{m}^{2}$ units lower to determine body fatness that is equivalent to that of Australian-Caucasian men who are classified as overweight or obese.

Table 3 shows the sensitivity and specificity of the WHO classification (with the cut-off point of $25 \mathrm{~kg} / \mathrm{m}^{2}$ ) and the WPRO classification (with the cut-off point of $23 \mathrm{~kg} / \mathrm{m}^{2}$ ) for the study group. The results showed that when the WHO classification was applied to Japanese men, only $33.3 \%$ of those who have $\% \mathrm{BF}$ of above 20 were identified, whereas using the WPRO classification, $64.7 \%$ of Japanese men with a $\% \mathrm{BF}$ of above 20 were identified. By comparison, applying

Table 3. Difference in sensitivity and specificity of the WHO and Western Pacific Region of WHO (WPRO) BMI classifications

\begin{tabular}{lcccc}
\hline & \multicolumn{3}{c}{ Percentage body fat by anthropometryll } \\
\cline { 2 - 5 } & \multicolumn{2}{c}{ Japanese (\%) } & \multicolumn{2}{c}{ Australian (\%) } \\
\hline $\mathrm{BMI}(\mathrm{WHO}$ classification) & $<20$ & $\geq 20$ & $<20$ & $\geq 20$ \\
$<25 \mathrm{~kg} / \mathrm{m}^{2}$ & $\mathbf{9 7 . 8}$ & 66.7 & $\mathbf{8 7 . 4}$ & 30.0 \\
$\geq 25 \mathrm{~kg} / \mathrm{m}^{2}$ & 2.2 & 33.3 & 12.6 & $\mathbf{7 0 . 0}$ \\
$\mathrm{BMI}(\mathrm{WPRO}$ classification) & $<20$ & $\geq 20$ & $<20$ & $\geq 20$ \\
$<23 \mathrm{~kg} / \mathrm{m}^{2}$ & $\mathbf{8 6 . 8}$ & 35.3 & $\mathbf{6 0 . 2}$ & 10.0 \\
$\geq 23 \mathrm{~kg} / \mathrm{m}^{2}$ & $13 . \cdot 2$ & $\mathbf{6 4 . 7}$ & 39.8 & $\mathbf{9 0 . 0}$ \\
\hline
\end{tabular}

\| According to previous recommendations (Nagamine, 1972; Wilmore et al. 1986), $20 \%$ body fat was used as a cut-off point for overweight for adult men. True positive and true negative values are printed in bold. the WHO classification to Australian-Caucasian men allowed the identification of $70 \%$ of those who had a $\% \mathrm{BF}$ of 20 and above, this value increasing to $90 \%$ if the WPRO classification was used. Hence it can be assumed that the WHO classification is appropriate for Australian-Caucasian men but not for Japanese men, if the sensitivity of the test is the major criteria.

\section{Discussion}

This study examined ethnic differences in the relationship between BMI and body fat deposition expressed as \%BF using Japanese and Australian-Caucasian adult men. Previous studies have found that Asians, including Chinese and MalaySingaporeans, have a greater amount of body fat than Caucasians at the same BMI values (Wang et al. 1994; Deurenberg et al. 2002). The current study supported the findings from these previous studies. The Japanese men in this study had a higher \% BF even though their BMI was within the normal range by the WHO classification.

In the present study, Japanese men had the same mean \%BF as Australian-Caucasian men but lower BMI values. Using the 'best fit' equation obtained from the current study, the BMI values at which the Japanese men could be expected to have the same \%BF that Australian Caucasian men had at BMI values of $25 \mathrm{~kg} / \mathrm{m}^{2}$ (WHO pre-obese) and $30 \mathrm{~kg} / \mathrm{m}^{2}$ (WHO obese class I) were 23.5 and $28.2 \mathrm{~kg} / \mathrm{m}^{2}$, respectively. That is, the equivalent BMI cut-off points were approximately $1.5 \mathrm{~kg} / \mathrm{m}^{2}$ units lower in the Japanese population. This indicates that application of the WHO classification to Japanese men may underestimate the proportion of the population who are obese. In comparison to the WHO classification, the WPRO classification that was proposed specifically for Asians and those living in the Pacific region (WHO/IASO/ IOTF, 2000) appropriately classifies BMI values of 23.5 and $28.2 \mathrm{~kg} / \mathrm{m}^{2}$ into the categories of 'overweight (at risk)' and 'obese class I'.

The JASSO classification was based on the level of health risk observed in epidemiological studies. In a study of 3582 Japanese men aged between 30 and 59 years, Tokunaga et al. (1988) found that Japanese had the lowest health risk at a BMI value of $22.2 \mathrm{~kg} / \mathrm{m}^{2}$. Yoshiike et al. (2000) conducted a metaanalysis of fifteen cohort studies with a total sample size of 151720 subjects (79 766 men and 71954 women), aged between 30 and 79 years, to examine the risk of developing health problems such as hypertension and high blood cholesterol, glucose and triacylglycerol levels. After controlling for confounding variables, the study compared the odds ratio of the health risks of seven BMI categories $(<16,16-17.9$, $\left.18-19 \cdot 9,24-25 \cdot 9,26-27 \cdot 9,28-29 \cdot 9,>30 \mathrm{~kg} / \mathrm{m}^{2}\right)$, using the BMI category of $20-24 \mathrm{~kg} / \mathrm{m}^{2}($ median $=22)$ as the baseline. The results indicated a significant increase in health risk as BMI increased. From these results, JASSO stated that a BMI of $22 \mathrm{~kg} / \mathrm{m}^{2}$ is the optimal value for Japanese adults in order to maintain the lowest health risk. JASSO further proposed that 'standard body mass' should be derived from a BMI value of $22 \mathrm{~kg} / \mathrm{m}^{2}$ (i.e. standard body mass $=22$ (height in meters) ${ }^{2}$ ) and recommended that Japanese maintain the body mass calculated by this equation to maintain health.

In our study, the BMI of Japanese men equivalent to a BMI of $25 \mathrm{~kg} / \mathrm{m}^{2}$ in Caucasians (when comparing \%BF) was 
$23.5 \mathrm{~kg} / \mathrm{m}^{2}$. This value is consistent with the studies by Tokunaga et al. (1988) and Yoshiike et al. (2000). In the future, epidemiological studies of health risk and adiposity should include measures of $\% \mathrm{BF}$ as well as BMI. This would further assist in defining BMI cut-off levels for risk. As obesity is defined as a condition of excessive fat deposition (WHO/ IASO/IOTF, 2000), actual body composition data, in conjunction with epidemiological data, should be used to set the BMI cut-off points in order to improve the specificity of BMI when it is used as a screening tool for overweight and obesity. To support the utility of lower BMI cut-off points for Japanese men, the current study showed an improvement in detecting Japanese men with an excessive amount of body fat when the WPRO classification was used $(64.7 \%)$, compared with the result using the WHO classification $(33 \cdot 3 \%)$.

The findings of the current study are supported by the results of Hsieh et al. (2000), who examined the degree of central fat accumulation using the waist-to-height ratio together with lifestyle variables in 2668 men. For individuals with higher levels of abdominal fat, they found an increasing risk of developing various health problems even within the BMI range of $20-24 \mathrm{~kg} / \mathrm{m}^{2}$. In addition, a recent study of a large Japanese sample of wider age range (20-79 years old; Ito et al. 2003) indicated that the cut-off point of BMI for Japanese from body composition assessments using anthropometry and DXA in relation to cardiovascular risk was around $23.5 \mathrm{~kg} / \mathrm{m}^{2}$ for men. Both studies reinforce the importance of determining BMI cut-off points after a consideration of body composition data.

No study to date has examined the BMI-\%BF relationship specifically for young Japanese men. The findings of the current study suggest that using BMI with the ordinal WHO or JASSO classification would largely misclassify young adult Japanese men, who have a high total body fat level. To reduce the misclassification of overweight and obesity in this population, it is recommended that a classification is used that reflects an appropriate BMI-\%BF relationship for Japanese men. From the currently available classifications for Japanese individuals (Table 1), the WPRO classification proposed by the WHO/IASO/IOTF (2000) provides the most appropriate BMI cut-off points to define overweight and obesity for this specific group. An alternative would be to use the BMI values of 23.0 and $27.5 \mathrm{~kg} / \mathrm{m}^{2}$, values chosen by the WHO as the cut-off points for public health action in their most recent report (WHO, 2004).

One limitation of the current study is that data were only collected on young men. Furthermore, owing to the relatively small sample size, the results of the current study may not be generalizable to the wider population. Future research should include both male and female subjects and use a larger sample size. The current study did not show any significant differences in the BMI-\%BF relationship between Japanese men living in different countries. This could be because of a minimum impact of environment on the physique of Japanese men because of their already Westernized lifestyle in Japan, or because this group had not lived in Australia for long enough to alter their physique.

To further examine environmental influences on the relationship, a longitudinal study that follows up Japanese men living overseas to monitor any changes in body composition over time is required. In addition, the calculated $\% \mathrm{BF}$ from the anthropometric equation that was used in the current study has unknown validity. It is therefore recommended that the current findings be confirmed using advanced body composition methods such as DXA in future studies. Furthermore, a limited number of cross-ethnic or cross-cultural studies have been undertaken using Japanese subjects. It is recommended that further comparisons of Japanese living in different countries and regions be completed to assess any environmental impact on their BMI-\%BF relationships.

\section{Conclusion}

The current study showed ethnic differences in the BMI-\%BF relationships between Japanese and Australian-Caucasian men. The Japanese men had a greater \%BF than the Australian-Caucasian men at any given BMI value. This indicates that Japanese men may be at greater risk of developing health conditions associated with excessive fat deposition at lower BMI values than Australian-Caucasian men. When using the BMI as a screening tool for obesity, such ethnic differences in the BMI-BF relationships should be considered. It is strongly recommended that studies use the classification system with BMI cut-points relevant to the body composition of the ethnic group being studied.

\section{Acknowledgements}

The authors express their gratitude to Associate Professor M. Ouchi (School of Engineering), Miss T. Masuda and Miss T. Nishiwaki (School of Human Science and Environment) of the University of Hyogo, who assisted with recruitment of the subjects and data collection in Japan.

\section{References}

Bei-Fan Z (2002) Predictive values of body mass index and waist circumference for risk factors of certain related diseases in Chinese adults: study on optimal cut-off points of body mass index and waist circumference in Chinese adults. Asia Pacific J Clin Nutr 11, S685-S693.

Bland JM \& Altman DG (1986) Statistical methods for assessing agreement between two methods of clinical measurement. Lancet 1, 307-310.

Chang C-J, Wu C-H, Chang C-S, Yao W-J, Yang Y-C, Wu J-S \& Lu F-H (2003) Low body mass index but high percent body fat in Taiwanese subjects: implications of obesity cutoffs. Int J Obes Relat Metab Disord 27, 253-259.

Deurenberg P, Bhaskaran K \& Lian PL (2003) Singaporean Chinese adolescents have more subcutaneous adipose tissue than Dutch Caucasians of the same age and body mass index. Asia Pacific $J$ Clin Nutr 12, 261-265.

Deurenberg P, Deurenberg-Yap M \& Guricci S (2002) Asians are different from Caucasians and from each other in their body mass index/body fat per cent relationship. Obes Rev 3, 141-146.

Deurenberg P, Yap M \& van Staveren WA (1998) Body mass index and percent body fat: a meta analysis among different ethnic groups. Int J Obes 22, 1164-1171.

Deurenberg-Yap M, Chew SK \& Deurenberg P (2002) Elevated body fat percentage and cardiovascular risks at low body mass index levels among Singaporean Chinese, Malays and Indians. Obes Rev 3, 209-215. 
Deurenberg-Yap M, Schmidt G, van Staveren WA, Hautvast JGAJ \& Deurenberg P (2001) Body fat measurement among Singaporean Chinese, Malays and Indians: a comparative study using a fourcompartment model and different two-compartment models. $\mathrm{Br} J$ Nutr 85, 491-498.

Durnin JVGA \& Womersley J (1974) Body fat assessed from total body density and its estimation from skinfold thickness: measurements on 481 men and women aged from 16 to 72 years. Br J Nutr 32, 77-97.

Fogelholm M \& Lichtenbelt WVM (1997) Comparison of body composition methods: a literature analysis. Eur J Clin Nutr 51, 495-503.

Gallagher D, Heymsfield SB, Heo M, Jebb SA, Murgatroyd PR \& Sakamoto Y (2000) Healthy percentage body fat ranges: an approach for developing guidelines based on body mass index. Am J Clin Nutr 72, 694-701.

Garn SM, Leonard WR \& Hawthorne VM (1986) Three limitations of the body mass index. Am J Clin Nutr 44, 996-997.

Gore C, Norton K, Olds T, Whittingham N, Birchall K, Clough M, Dickerson B \& Downie L (1996) Accreditation in anthropometry: an Australian model. In Anthropometrica, pp. 395-411 [K Norton and T Olds, editors]. Sydney: University of New South Wales Press.

Hsieh SD, Yoshinaga H, Muto T, Sakurai Y \& Kosaka K (2000) Health risk among Japanese men with moderate body mass index. Int $J$ Obes 24, 358-362.

Ito H, Nakasuga K, Ohshima A, Maruyama T, Kaji Y, Harada M, Fukunaga M, Jingu S \& Sakamoto M (2003) Detection of cardiovascular risk factors by indices of obesity obtained from anthropometry and dual-energy X-ray absorptiometry in Japanese individuals. Int $J$ Obes 27, 232-237.

Jia WP, Xiang KS, Chen L, Lu JX \& Wu YM (2002) Epidemiological study on obesity and its comorbidities in urban Chinese older than 20 years of age in Shanghai, China. Obes Rev 3, 157-165.

Kagawa M, Kerr D \& Binns C (2003) Ethnic differences in the BMI-\%BF relationships between young Japanese and AustralianCaucasian men living in Australia using dual-energy x-ray absorptiometry. Asia Pac J Public Health 15, S27-S32.

Kenkou Eiyou Jouhou Kenkyukai (2003) Kokumin eiyou no genjou The National Nutrition Survey in Japan, 2001 [in Japanese]. Tokyo: Daiichi Shuppan.

Kistorp CN \& Svendsen OL (1998) Body composition results by DXA differ with manufacturer, instrument generation and software version. Appl Radiat Isot 49, 515-516.

Ko GTC, Tang J, Chan JCN, Sung R, Wu MMF, Wai HPS, \& Chen R (2001) Lower BMI cut-off value to define obesity in Hong Kong Chinese: an analysis based on body fat assessment by bioelectrical impedance. Br J Nutr 85, 239-242.

Lee ZSK, Critchley JAJH, Ko GTC, Anderson PJ, Thomas GN, Young RP, Chan TY, Cockram CS, Tomlinson B \& Chan JC (2002) Obesity and cardiovascular risk factors in Hong Kong Chinese. Obes Rev 3, 173-182.

Li G, Chen X, Jang Y, Wang J, Xing X, Yang W \& Hu Y (2002) Obesity, coronary heart disease risk factors and diabetes in Chinese: an approach to the criteria of obesity in the Chinese population. Obes Rev 3, 167-172.

Matsuzawa Y, Inoue S, Ikeda Y, et al. (2000) Atarashii himan no hantei to himanshou no shindan kijun (New diagnostic criteria for obesity and obesity disease) [in Japanese]. Journal of Japan Society for the Study of Obesity 6, 18-28.
Moon OR, Kim NS, Jang SM, Yoon TH \& Kim SO (2002) The relationship between body mass index and the prevalence of obesity-related diseases based on the 1995 National Health Interview Survey in Korea. Obes Rev 3, 191-196.

Nagamine S. (1972) Hikashibou kara no himan no hantei (Diagnosis of obesity from subcutaneous fat deposition [in Japanese]. J Jap Med Assoc 68(9), 919-924.

National Health and Medical Research Council (1999) National Statement on Ethical Conduct in Research Involving Humans Aus Inf Canberra ACT.

Norgan NG \& Ferro-Luzzi A (1982) Weight-height indices as estimators of fatness in men. Human Nutrition 36C, 363-372.

Norton K \& Olds T (1996) Anthropometrica. Sydney: University of New South Wales Press.

Roche AF (1996) Anthropometry and ultrasound. In Human body composition, pp. 167-189 [AF Roche, SB Heymsfields and TG Lohman, editors]. Champaign, IL: Human Kinetics.

Ross WD, Crawford SM, Kerr DA \& Ward R (1988) Relationship of the body mass index with skinfolds, girths, and bone breadths in Canadian men and women aged 20-70 years. Am J Phys Anthropol 77, $169-173$.

Schaefer F, Georgi M, Wiihl E \& Scharer K (1998) Body mass index and percentage fat mass in healthy German schoolchildren and adolescents. Int J Obes 22, 461-469.

Siri WE (1961) Body volume measurement by gas dilution. In Techniques for measuring body composition, pp. 108-117 [J Brozek and A Henschel, editors]. Washington, DC: National Academy of Sciences.

Tokunaga M, Matsuzawa Y, Kotani K, Fujioka S, Kawamoto T, Obata T, Mouno Y \& Tarui S (1988) Shuzu no gappeishou wo kouryo shita risou taiju (An ideal body weight that considered various complications from obesity) [in Japanese]. Dai 9 kai nihon himan gakkai kiroku 236-238.

Wang J, Thompson JC, Russel M, Burastero S, Heymsfield S \& Pierson RN Jr (1994) Asians have lower body mass index (BMI) but higher percent body fat than do whites: comparisons of anthropometric measurements. Am J Clin Nutr 60, $23-28$.

Werkman A, Deurenberg-Yap M, Schmidt G \& Deurenberg P (2000) A comparison between composition and density of the fat-free mass of young adult Singaporean Chinese and Dutch Caucasians. Ann Nutr Metab 44, 235-242.

Wilmore JH, Buskirk ER, Ri Girolamo M \& Lohman TG (1986) Body composition-a round table. Phys Sportsmed 14(3), 144-162.

WHO (1997) Obesity: Preventing and Managing the Global Epidemic. Geneva: WHO/NUT/NCD.

WHO (2004) Appropriate body-mass index for Asian populations and its implications for policy and intervention strategies. Lancet $\mathbf{3 6 3}$ $157-163$

WHO/IASO/IOTF (2000) Asia-Pacific Perspective: Redefining obesity and its Treatment. Melbourne: Health Communications Australia.

Yoshiike N, Nishi N, Matsushima S, et al. (2000) Body mass index ni motozuku himan no teido to tounyoubyou, kouketsuatsu, koushikesshou no kikeninshi tono kanren -tashisetsu kyoudou kenkyu ni yoru ekigaku teki kentou (Associations between obesity and risk factors of diabetes, hypertension and hyperlipidaemia based on body mass index - epidemiological study from multi-facility collaborative study) [in Japanese]. Journal of Japan Society for the Study of Obesity 6, 4-17. 